\title{
Supervision as a model of inclusive education retraining and professional advancement of the school community
}

\author{
Kateryna Bondar*, and Olena Shestopalova \\ Kryvyi Rih State Pedagogical University, Department of Practical Psychology, 79a Heroiv ATO Str., Kryvyi Rih, 50086, Ukraine
}

\begin{abstract}
In this article, we describe the model of supervision in support of the Education Reform in Ukraine and the retraining of the school's key stakeholders in an inclusion: the case of Kryvyi Rih. Empirical study has introduced a model of retraining through a socio-political and educational description of the current situation in Kryvyi Rih. That is why 124 key stakeholders from 20 schools with inclusive education were tested to plan the implementation model of supervision (teachers, tutors, staff, psychologists and parents from 7 districts of Kryvyi Rih were invited to participate). In this article, we present a different approach to supervisory interagency groups and understanding, with the focus on the model supervision retraining of inclusive education professionals. The supervision consists of four stages: case report, exchange, conceptualization, summary. For successful work, we propose in the article an adaptation of an unstructured interview by a specialist who describes the situation of training supervision. The analysis of the organizational, methodological and information retraining system, the implementation of the pilot project of supervisory groups for the psycho-educational support team in inclusive education allowed to offer the supervision program: I. Training of the team members to work with the goals of the individual child development plan: working with tools for preparation of the case; II. The main features of observing the lesson; III. Analysis of environmental factors; IV. Oversee team support.
\end{abstract}

\section{Introduction}

The concept of supervision in inclusive education in Ukraine based on national education reform and the new law. The Education Reform (Education act of Ukraine Document 2145-VIII, effective, current version adopted on 05.09.2017) provides for a systematic transformation of the sector, the primary objective of which is the new high quality of education on all levels: ranging from the elementary school up to the higher education establishments. In particular, Article 6. Basic principles of state policy in the field of education and principles of educational activities and Article 19. The education of individuals with special needs are relevant to this research [11]. For this reason, a shortage of professionals, ensuring stable (sustainable) transition to the new system of teaching and providing educational services is a priority for securing standards for the implementation of education reform. That is why the main weaknesses of supporting education reform is a general scarcity of algorithms of retraining for key stakeholders in inclusive education.

This study refers to scientific research, which describes models supervision retraining of inclusive education professionals (C. Acedo, O. Akimova, S. Alila, I. Goodman, L. Ferguson, Z. Leniv, G. Lindsay, I. Hardy, T. Ryan, S. Symeonidou and others) considered consultative and collaborative models of team's support [1-10]. The meaningful idea of inclusion in New Ukrainian School, that teachers should be able to individualize and differentiate the educational process in terms of learning styles, abilities and additional needs of all children in education [12]. In addition to allowing more flexibility in school-wide curriculum development, inclusive education practices were made mandatory for children with special educational needs $[2,6,5]$. Therefore, the teacher needs the support of key stakeholders or collaborative team (administration, families, service staff, assistants and other specialists from the team) to guarantee this individualization of the educational process [7-8].

According to other researchers, a fundamental principle a successful program of retraining inclusive education professionals, one should take into account the world experience, and rely on the new paradigm of the European Education Area [5, 7, 8]. However, traditional forms leave the team approach during retraining and active training out of the account. That is to say, that outdated forms of retraining do not stimulate the school communities in Ukraine to fundamentally change their attitude towards their participation in the field of inclusive education according to European Standards. Consequently, the educational supervision for collaborative team is a dialogical process based on human values and understanding, and equal constructive relations between a supervisor and a recipient of supervision, which is targeted at accumulating the unique personal knowledge in a particular educational

\footnotetext{
* Corresponding author: katerynabondarr@gmail.com
} 
situation and personal growth of both parties [1, 3, 4]. Thus, educational supervision creates a model retraining of the school's key stakeholders in inclusion.

The purpose of supervision is to increase the singlemindness of professional actions, upgrade qualification and improve the degree of satisfaction with the own work [3]. It means the subject of educational supervision is the analysis of the conscious and unconscious potential abilities of the key stakeholders. Educational supervision is possible in various forms [1]. The coteaching group is a group form of the training for specialists-beginners (provides for the thematic focus) and intended for in-depth training and solving professional problems of key stakeholders [9]. Additionally, the co-teaching group carried out in a scheduled manner under the management of a supervisor. A thematic seminar is a group form of the work, in which the specialists of one profile of activities participate, for example, psychologists, and it is designed for discussing various professional problems, as well as carried out in a scheduled manner under the management of a supervisor [1,9]. Interagency group of the supervisory work, the purpose of which is a group discussion of professional problems of the different team specialists, regardless of their experience, is conducted in a scheduled manner and under the management of a supervisor [1, 3, 9]. Additionally, educational supervision includes modeling and co-teaching the educational activities for children with special educational needs (SEN) for all participants of the team $[4,1]$. Consequently, successful supervision should help the team members to understanding better the philosophy, main purpose, and practice of inclusive education, to find out about external and internal resources of activities of the collaborative team's participants in inclusive education.

Fundamentally, supervision, as an effective form of the collaborative and co-teaching model, is educating key stakeholders to solve difficulties and search for fresh ideas as well as effective educational solutions. According to the Standard Regulations on Supervision over Implementation of the Concept "New Ukrainian School", the educational supervision is a relatively new line of work with human resources for the Ukrainian educational system [11-12]. That is why there is a general scarcity of studies analyzing models of supervision in support of the Education Reform in Ukraine and the retraining of the school's key stakeholders in an inclusion.

The purpose of this study was an adaptation of the model of educational supervision to the Ukrainian educational system.

\section{Method}

The algorithm for conducting supervisory interagency groups includes four steps (Fig. 1) [3, 9, 10]. The first step is the report of the case from someone of key stakeholders and his/her formulation of a request. At this step, questions are asked by the group members to the presenter and aimed at clarifying the information about the child and educational situation are desirable. Then, the group discussion takes place, when the presenter is silent: the group members discuss professional actions without talking about the presenter's personal qualities.

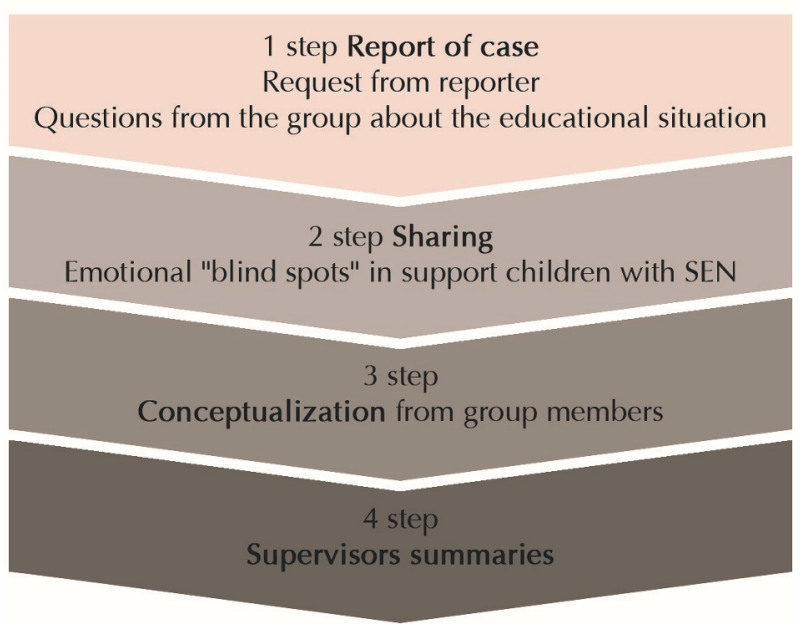

Fig. 1. Model of educational supervision.

In the second step, the group members share their feelings about the educational situation spontaneously. This step is important for establishing a safe atmosphere in the group and contributes to the awareness by the supervised "blind spots" in the work.

In the conceptualization step, the supervisor questions each group member about his/her concept of the origin of a problem, which the child with special educational needs has, and its remedy. No position is disputed or condemned by the supervisor and other group members.

In the fourth step, the supervisor summarizes the method of the presenter's work and proposes his/her concept of clarifying problems in the work with the child as well as optimal tactics of the work of options as effective educational solutions.

To prevent resistance of the group members and to distinguish themselves from the traditional methodical work, the following rules of work are introduced: 1) bringing his/her case for the consideration, the teacher has the right to determine what he/she wants from supervision; 2) the teacher forms himself/herself his/her request and expectation from the group and experts; 3 ) the "Stop" rule, which allows to interrupt the discussion at any time, or not to answer questions that cause your rejection for one or another reason, and protects against the disclosure of an unwanted information.

\section{Implementation of the model of educational supervision}

\subsection{Background}

The implementation of the model began with working meetings of the planning team (in January-April 2019). The work of planning team aimed at developing a concept for supporting inclusive education in Kryvyi Rih in cooperation between Deutsche Gesellschaft für Internationale Zusammenarbeit (GIZ) GmbH, Department of Education and Science of the Executive Committee of the Kryvyi Rih City Council and the 
Kriviy Rih State Pedagogical University (KSPU), with the participation of the consultant Karsten Zehner. Structure of advanced training for educators in the premises of the KSPU was discussed: procedure for interaction with the education department, regulatory framework and stages of preparation of supervision.

Implementation of the model of educational supervision for developing inclusive education in the schools of Kryvyi Rih. Methods of the supervision groups are by the Standard Regulations on Supervision for Implementation of the Concept "New Ukrainian School" (developed by the Ministry of Education of Ukraine and the SSI "Institute of Education Content Modernization"). The basic idea of supervision capacity development and practicing teaching skills for key stakeholders, who work with different categories of children with special educational needs in the schools of the city of Kryvyi Rih - "Introduction of inclusive education at the local level".

\subsection{Summary}

Empirical study has introduced a model of retraining through a socio-political and educational description of the current situation in Kryvyi Rih. That is why 124 key stakeholders from 20 schools with inclusive education were tested to plan the implementation model of supervision (teachers, tutors, staff, psychologists and parents from 7 districts of Kryvyi Rih were invited to participate). We consider the following to be the purpose of conducting supervision groups:

1) improve the quality of training for providing highquality educational services in the context of inclusion for the teaching staff of general education institutions in the city of Kryvyi Rih according to the ideas of the New Ukrainian School and the new Law on Education;

2) using the team approach and principles of work of the supervision group, establish creative atmosphere for discussing the following problematic topics: specifics of identifying objectives and planning how to fulfill these in an individual development program; establishing learning behavior in children with SEN; autism spectrum disorders, etc.; difficulties in relationships with parents of children with SEN and involving them into the support team; organizational and managerial difficulties (structuring forms of education or additional educational services for children with SEN); personal problems of a specialist in connection with his/her professional situation;

3) present during the round-table discussion results of the work of supervision groups on inclusive education issues, held with the support of GIZ in Kryvyi Rih, get feedback and discuss issues and recommendations.

4) ensure during the regional round-table discussion gathering of ideas and discussion of opportunities for further extension, expansion, and institutionalization of the capacity development program in the field of inclusive education in Kryvyi Rih (further requirements, roles, and responsibilities, partner cooperation, ways of implementation, necessary resources).

\subsection{Outcome of the planning team}

The study was originally conducted on key stakeholders' experience. The first step of planning the implementation model of supervision was testing responses (key stakeholders from schools with inclusive education in Kriviy Rih). In the study, we relied on the questionnaire of responses' experience in inclusive education (124 persons, 120 - women, 4 - men) (Fig. 2).

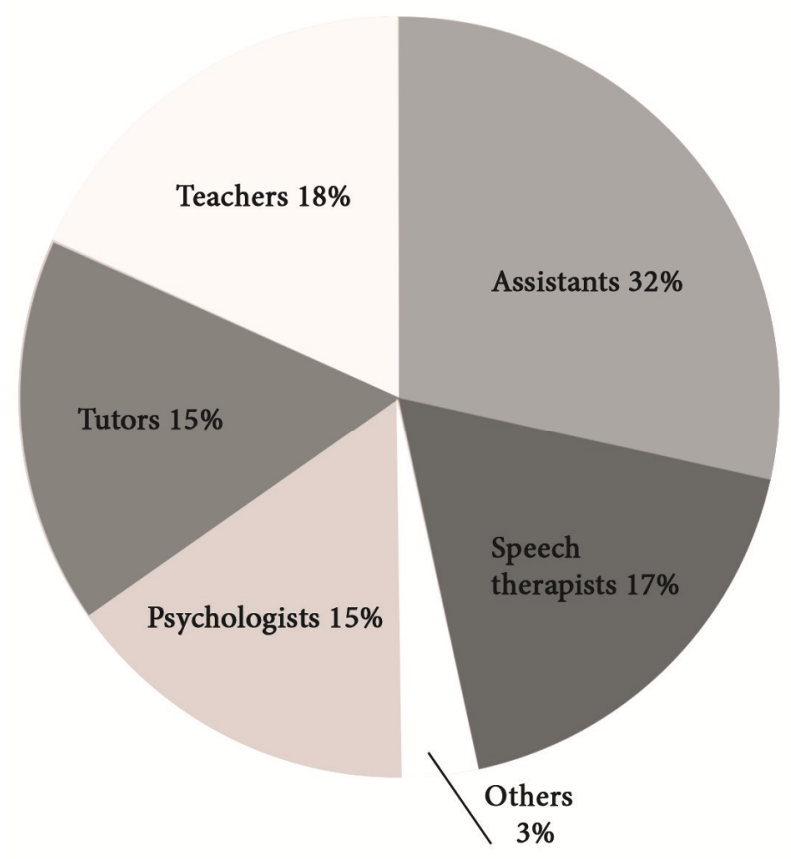

Fig.2. Distribution of professional groups among supervision participants.

The second step was the analysis of the answers to responses. For this evaluation, we focused only on the responses: an educational experience of working with children with SEN, background knowledge, emotional barriers in communicating, expectations from the retraining. According to the distribution of an educational experience of working with children with SEN, the selection is as follows $73 \%$ have experience of support children with SEN, 27\% - specialists-beginners.

However, $80 \%$ of respondents answered that their knowledge of technologies, forms, and methods of education of children with special needs is not enough. Concerning the system retraining in special education, $64 \%$ have not improved their qualifications. It must be noted that only $14 \%$ of school team members have special education in the field of occupational therapy and special education (Table 1).

Table 1. Do you have special training in the field of inclusive education? $(n=124)$.

\begin{tabular}{|c|l|}
\hline Percentage $\%$ & \multicolumn{1}{|c|}{ Answer } \\
\hline $\mathbf{1 4 \%}$ & I have a special education \\
\hline $\mathbf{4 4 \%}$ & I do not have a special education \\
\hline $\mathbf{5 \%}$ & I received vocational retraining in the area \\
\hline $\mathbf{2 6 \%}$ & I took further training courses in this area \\
\hline $\mathbf{1 2 \%}$ & $\begin{array}{l}\text { I did not take further training courses in this } \\
\text { area }\end{array}$ \\
\hline
\end{tabular}


Most stakeholders consider their background knowledge insufficient and want to continue the process of further training (Tables 2-3).

Table 2. To what extent are you familiar with the developmental characteristics of the children with the different types of disabilities (Please, put "+" if your answer is "Yes" $(n=124)$.

\begin{tabular}{|c|c|c|c|c|}
\hline & 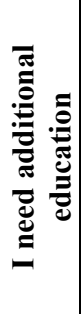 & 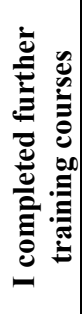 & 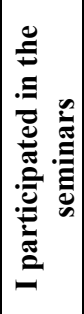 & 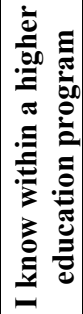 \\
\hline Behavioral disorders & $11 \%$ & $23 \%$ & $19 \%$ & $17 \%$ \\
\hline Speech impediments & $15 \%$ & $16 \%$ & $15 \%$ & $12 \%$ \\
\hline Intellectual disabilities & $14 \%$ & $16 \%$ & $20 \%$ & $17 \%$ \\
\hline Vision impairments & $13 \%$ & $6 \%$ & $12 \%$ & $17 \%$ \\
\hline Hearing impairments & $14 \%$ & $10 \%$ & $12 \%$ & $17 \%$ \\
\hline Musculoskeletal disorders & $15 \%$ & $16 \%$ & $8 \%$ & $15 \%$ \\
\hline Autism spectrum disorder & $20 \%$ & $13 \%$ & $15 \%$ & 87 \\
\hline
\end{tabular}

Table 3. For which group of children with special needs do you want to learn a teaching practice in the first place? $(n=124)$.

\begin{tabular}{|c|l|}
\hline Percentage \% & \multicolumn{1}{|c|}{ Answer } \\
\hline $\mathbf{1 0 \%}$ & For children with musculoskeletal disorders \\
\hline $\mathbf{1 3 \%}$ & $\begin{array}{l}\text { For children with sensory disabilities (hearing, } \\
\text { vision) }\end{array}$ \\
\hline $\mathbf{9 \%}$ & For children with intellectual disabilities \\
\hline $\mathbf{1 6 \%}$ & For children with speech impediments \\
\hline $\mathbf{2 5 \%}$ & For children with behavioral disorders \\
\hline $\mathbf{2 6 \%}$ & For children with intellectual disabilities \\
\hline
\end{tabular}

Among the typical difficulties in interacting with professionals is the following - about $18 \%$ of respondents have emotional barriers in communicating with children with SEN, and for $16 \%$ of participants of the groups it is difficult to communicate with parents of these children, sometimes difficult for $4 \%$ of the respondents. School team members are generally willing to share their experiences, but some individuals do not care.

Consequently, a holding of workshops, the exchange of experience, participation in supervision groups prevails among the typical expectations for retraining of inclusive education professionals. The second place is taken by the improvement of methodological and procedural training in teaching children with SEN (Table 4).

It resulted in elaborating an understanding of supervision procedures, methods of material adaptation, and strategies for working with groups.

\subsection{Adaptation of the model of education supervision}

Adaptation of the model of educational supervision was held in Kryvyi Rih in April-November 2019. For this part of the research, we focused on the selection of educators from 20 schools (124 persons) on 15 groups.
The following has been developed and given to team members to compile a case description:

- adapted version of the unstructured specialist's interview, in which she/he describes her/his case for supervision in a Balint group;

- protocol of types of interaction of the support team during the week;

- protocol of registering learning behavior;

- video presentation of components of learning behavior, working with social stories and visual simulation of learning rules of conduct in an educational institution;

- protocol of the weekly observation of the effectiveness of the material modification;

- standardized overseeing table for behavioral difficulties of children with SEN.

Table 4. What kind of help do you expect from the retraining of inclusive education professionals? $(n=124)$.

\begin{tabular}{|l|c|c|}
\hline \multicolumn{1}{|c|}{ Typical Answers } & $\begin{array}{c}\text { Percentage } \\
\text { \% }\end{array}$ & Rating \\
\hline $\begin{array}{l}\text { Methodological and procedural help in } \\
\text { teaching children with SEN }\end{array}$ & 36,45 & 2 \\
\hline Maintaining business documentation & 3,85 & 5 \\
\hline $\begin{array}{l}\text { Case studies, any practice-oriented } \\
\text { training, experience exchange, } \\
\text { supervisions }\end{array}$ & 40,4 & 1 \\
\hline $\begin{array}{l}\text { Detailed characteristics of specific } \\
\text { categories of children with SEN, work of } \\
\text { the support team, forms of cooperation } \\
\text { with the teacher's assistant, diagnostics } \\
\text { and correction technologies }\end{array}$ & 13,5 & 3 \\
\hline $\begin{array}{l}\text { Close collaboration with the inclusive and } \\
\text { resource center or the employee of this } \\
\text { center }\end{array}$ & 5,8 & 4 \\
\hline
\end{tabular}

It shall be noted that this is one of the first projects of this kind in Ukraine.

\subsubsection{Interview}

For the successful work on 1-2 steps of supervision, we offer the adapted version of the interview of the specialist, who describes the situation for the educational supervision (developed by authors). The interview contains 12 questions that evaluate the respondents' professional activity (professional and personal expectations). The study utilized the Interview to assess respondents' positions on professional expectations in inclusive supporting the child.

A pilot study with a small sample of teachers was conducted to establish whether questions were appropriate and understandable for the intended target group. The Interview provided indicators of the position of participants on two forms and six subdimensions of professional expectations: 1. professional expectations (6 items, Cronbach's $\alpha=0.73$ ); 2. personal expectations (6 items, 11, Cronbach's $\alpha=0.70$ ). For educators, psychologists, social employees (educators), teaching assistants (the positions are hereinafter referred to as "specialist"):

1. How satisfied is the specialist with his/her actions in the professional situation?

2. On what basis the specialist carried out the choice of his/her tactics of interaction with the child? 
- How did he/she implement these tactics?

- What are the outcomes of such interaction?

- What could be done differently, if this opportunity were to happen?

3. What feelings and thoughts did the specialist have in the process of professional actions? For example, whether he/she felt irritation, anger, or frustration.

4. What body feelings did the specialist have during the difficult pedagogical situation? For example, muscle aches or abdominal discomfort.

5. What complicated (caused the emotional tension) the realization of professional activities, and at what point?

6. Who (in what "role") did the specialist feel he/she was in the process of professional actions? ("helping father (mother)"; equal, friend, "critical parent", another role).

7. Did the specialist have moments of the intense internal irritation to the child (one of the child's parents) in the process of interaction with his (her) and to what they related?

8. What did the specialist want to do in this case?

9. What factor, according to the specialist, is the problem related to?

- How exactly did I understand (imagine) the situation;

- What did I want in this situation;

- What did I feel in this situation;

- What did I do;

- What "should" I do?

10. What, according to the specialist, did the child (one of the child's parents) expect from the specialist's actions?

11. Are the emotional expectations of the child (one of the child's parents) equal to my abilities in this case?

12. How can one describe the problem that has arisen?

- Objective reasons (lack of experience, peculiarities of the child or its parents, etc.).

- Internal reasons (psychological impediments, severe emotional discomfort, frustration).

\subsubsection{Cases}

The result of supervision was mastering and intensification of application of theoretical knowledge and practical skills for analyzing typical complex cases of academic interaction in the context of inclusive education (school administration, child support team, specialists from the Inclusion and Resource Centre) (Table 5).

There were special cases of peculiarities of regulatory support of employment and public purchasing procedure, peculiarities of interactions with parents, announcement of the opening of an inclusive class, techniques for planning reasonable accommodation and universal design. According to the plan, during the introductory trainers analysed the procedure of supervision, the schemes of analysis of observations of the learning behavior, compiling social stories and practicing preparing an individual development program.

Consequently, the experience of conducting supervisory groups in Kryvyi Rih City revealed the typical requests in terms of implementing inclusive education (Table 4): 1) difficulties in understanding the problem of learning and development of the child with SEN; 2) difficulties in supporting and developing the child with SEN; 3) difficulties in dealing with the parents; 4) organizational difficulties (structuring of forms of education or additional educational services for children with SEN); 5) personal problems of the specialist in connection with the professional situation. That was also a supervision analysis of problems in children with autism spectrum disorders, including sexual education of such children, has been performed.

Table 5. Description of the inquiries of the Team specialists during supervisions $(n=124)$.

\begin{tabular}{|l|c|c|}
\hline \multicolumn{1}{|c|}{ Answers } & $\begin{array}{c}\text { Percentage } \\
\text { \% }\end{array}$ & Rating \\
\hline $\begin{array}{l}\text { Ambivalent perception of children with } \\
\text { SEN by the parents of other children }\end{array}$ & 8,0 & 4 \\
\hline $\begin{array}{l}\text { What to do, if the child with autism } \\
\text { spectrum disorders is distracted by } \\
\text { background noise at the lessons }\end{array}$ & 6,8 & 5 \\
\hline $\begin{array}{l}\text { Algorithm of the contact with the } \\
\text { "difficult" parents of children having } \\
\text { SEN, who avoid responsibility }\end{array}$ & 16,3 & 2 \\
\hline $\begin{array}{l}\text { Children's protest against setting } \\
\text { educational tasks and avoidance of } \\
\text { performing tasks due to difficult speech } \\
\text { problems }\end{array}$ & 21,1 & 1 \\
\hline $\begin{array}{l}\text { Refusal of educational tasks in the } \\
\text { learning of the child with SEN }\end{array}$ & 4 & 9 \\
\hline $\begin{array}{l}\text { "Escape from learning activities" and } \\
\text { immersion in the fantasy world of the } \\
\text { child with SEN }\end{array}$ & 3,3 & 11 \\
\hline $\begin{array}{l}\text { Strategies for teaching natural sciences } \\
\text { and mathematics for the child with SEN } \\
\text { in a secondary school }\end{array}$ & 3,7 & 12 \\
\hline $\begin{array}{l}\text { Systematic school failures as a } \\
\text { manifestation of spring exacerbation of } \\
\text { psycho-neurological disease }\end{array}$ & 3,8 & 10 \\
\hline $\begin{array}{l}\text { Age-specific features of inclusive } \\
\text { education for the child with hearing } \\
\text { impaired }\end{array}$ & 3,1 & 13 \\
\hline $\begin{array}{l}\text { Work of the Team in the training material } \\
\text { adaptation }\end{array}$ & 6,1 & 6 \\
\hline $\begin{array}{l}\text { Learning strategies in complex } \\
\text { difficulties }\end{array}$ & 3,0 & 14 \\
\hline $\begin{array}{l}\text { Low attentiveness and fatigue in children } \\
\text { with the asthenic syndrome }\end{array}$ & 2,3 & 15 \\
\hline $\begin{array}{l}\text { Professional burnout of specialists in the } \\
\text { Team }\end{array}$ & 4,4 & 7 \\
\hline $\begin{array}{l}\text { Dilemma of transferring the child from } \\
\text { the inclusive form of education to the } \\
\text { individual one }\end{array}$ & $\begin{array}{l}\text { The problem of the training material } \\
\text { adaptation in a secondary school in severe } \\
\text { dyslexia of the teenager. }\end{array}$ & 4,0 \\
\hline
\end{tabular}

\subsubsection{Results}

Analysis of the dynamics of the groups after the supervision based on the questionnaire of professional skills (developed by authors). The questionnaire contains 38 questions that evaluate the respondent's professional competences and skills in inclusive education on a scale of 1 (the skill is not mastered) to 5 (the skill is mastered). The questionnaire provided indicators of the position of participants on 5 scales of skills: 1. Supervision of 
complex cases (8 items, Cronbach's $\alpha=0.70)$; 2. Knowledge of key features of authorities of the support team of a child with SEN (10 items, Cronbach's $\alpha=0.69)$; 3. Work on the compilation and implementation of an individual development plan (IDP) (12 items, Cronbach's $\alpha=0.71$ ); 4. The resource/sensor rooms ( 8 items, Cronbach's $\alpha=0.62$ ).

Firstly, there was a positive growth of expertise concerning the following topics: "Supervision of complex cases" $(\mathrm{M}=4.31, \mathrm{SD}=0.47)$. Secondly, the scale "Knowledge of key features of authorities of the support team of a child with $\mathrm{SEN}$ " $(\mathrm{M}=3.15, \mathrm{SD}=0.57)$ indicates the heterogeneity of mastering skills about the team's work and its authorities. Therefore, practicing methods of coordination of the support team, purposes of compiling an IDP form a separate purpose of the supervision. Thirdly, the scale "Work on the compilation and implementation of an individual development plan (IDP)" ( $\mathrm{M}=3.78, \mathrm{SD}=0.57)$, indicates fluctuations in the mastering skills implementing an IDP. It is expedient to introduce a strategy for assessing the child's educational success, simplification/complication of the program in the supervision module. Lastly, the scale "The resource/sensor rooms" $(\mathrm{M}=2.47, \mathrm{SD}=0.46)$ indicates fluctuations in confidence in the theory and practice of occupational therapy in the resource / sensory rooms.

The study utilized the content analysis of professional skills (developed by authors). Content analysis technique was used to categorize the answers of the listeners ("What did you like the most? Please describe" - Fig. 3):
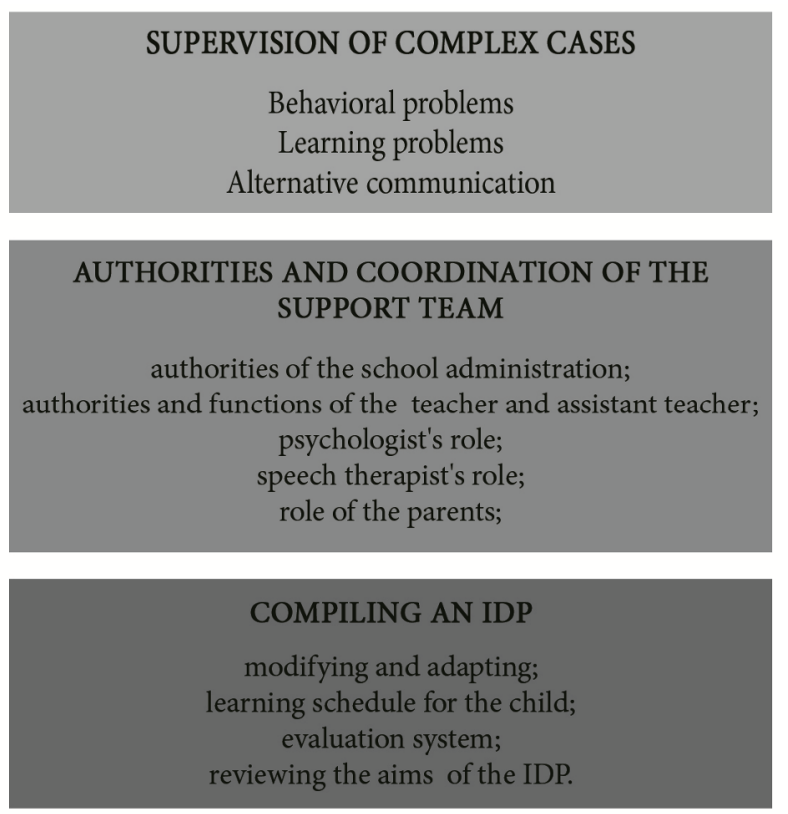

Fig. 3. Content analysis of answers from the respondents.

Cluster I "Supervision of complex cases": expanding the supervision module of problems in children with autism spectrum disorders, including sexual education; supervisions for team working with children with special language needs; supervisions for the frequency of meetings with children with special educational needs.
Cluster II "Coordination of the support team": video modeling of behavior; assembling groups according to the educational characteristics of children; psychodrama for key stakeholders for difficulties in establishing contact; peculiarities of interactions with parents.

Cluster III "Compiling an IDP": Practical exercises on the use of sensory equipment; a diagnostic protocol of the child's individuality; techniques for planning reasonable accommodation and universal design; case study.

\section{Conclusion}

Analysis of the system of organizational and methodological and informational retraining, implementation of the pilot project of advanced training courses in the form of supervision groups and training program for the team of psychological and educational support in inclusive education made it possible to offer a program of supervision (Fig. 4):

I module. Training members of the team to work with the objectives of the individual development plan (IDP) of a child: working with tools for preparing a case.

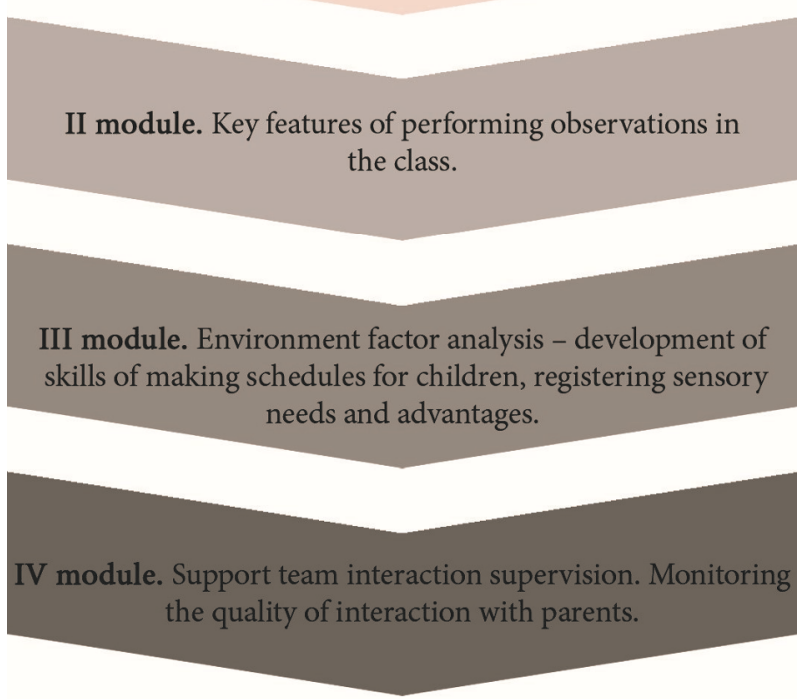

Fig. 4. Model supervision retraining of inclusive education professionals.

I module. Training members of the team to work with the objectives of the individual development plan (IDP) of a child: working with tools for preparing a case. Outline or plan of activities for a child within inclusive education in the school educational system.

Components of an individual development plan: available level of knowledge (academic knowledge) and functional skills - what are the success and achievements of a child when compiling an IDP; annual learning goals for children and how the school is going to monitor the progress; care and educational services, which will be rendered to the child. These can include special education, adjacent and auxiliary services, and a prolonged school year as well; time limits and conditions of the services: starting time, how often, for how long; 
accommodations, that is changes and adjustments of the child's learning environment; modifications, that is changes of contents and essence of the child's learning plan; how will the child participate in the (final) standard tests; how will the child be included into the work of the general education class, how will she/he participate in different types of activities.

II module. Key features of performing observations in the class. Educational behavior. Stages of formation of educational behavior. Modifying materials for the classes about the level of maturity of the learning behavior: preparation of classes as a separate case. Modifying assessment.

Registration of child's behavior: detecting a motivator, prevention techniques, error-free learning strategies, incentive schedules, use of hints, task changes, change of hints (antecedent package).

III module. Environment factor analysis development of skills of making schedules for children, registering sensory needs and advantages. Teaching how to introduce school rules for children. Social stories. Teaching school rules.

IV module. Support team interaction supervision. Monitoring the quality of interaction with parents.

In carrying out educational supervisions, the following methods have proven themselves: 1) case "A difficult child (its parents) for me", 2) development of skills of the non-violent communication, 3) group work to find solutions, 4) clarifying relations with the help of a supervisor, 5) training in the development of skills of observation and analysis of the child's behavior, 6) brainstorm.

\section{References}

1. C. Acedo, Preparing teachers for inclusive education. Prosp. 41, $301 \quad$ (2011). doi:10.1007/s11125-011-9198-2

2. O. Akimova, Osnovni aspekti inklyuzivnoyi osviti u pidgotovczi majbutnikh uchiteliv pochatkovikh klasiv (Main aspects of inclusive education in the education of future primary school teachers). Naukovi zapiski kafedry pedagogiki 35, 12-18 (2014)

3. S. Alila, K. Määttä, S. Uusiautti, How does supervision support inclusive teacherhood? International Electronic Journal of Elementary Education 8(3), 351-362 (2017)

4. I. Goodman, M. Brady, M. Duffy, J. Scott, N. Pollard, The effects of "bug-in-ear" supervision on special education teachers' delivery of learn units. Focus on Autism and Other Developmental Disabilities 23(4), 207-216 (2008). doi:10.1177/1088357608324713

5. L. Ferguson, International trends in inclusive education: The continuing challenge to teach each one and everyone, Eur. J. of SEN 23.2, 115 (2008). doi:10.1080/08856250801946236

6. Z. Leniv, Kognitivno-kompetetnisniy component gotovnosti asistenta vchitelya do komandnoyi vzaemodiyi $\mathrm{v}$ umovah inkluziyi (The cognitive competency component of the readiness of the assistant to the team's cooperation in inclusion). Actual. pitannya korr. osvity 13, 110-122 (2019)

7. G. Lindsay, Inclusive education: A critical perspective. Br. J. of Spec. Ed. 30(1), 3-12 (2003). doi:10.1111/1467-8527.00275

8. I. Hardy, S. Woodcock, Inclusive education policies: Discourses of difference, diversity and deficit. Int. J. of Incl. Ed., 19(2), 141-164 (2015). doi:10.1080/13603116.2014.908965

9. T. Ryan, J. Gottfried, Elementary supervision and the supervisor: Teacher attitudes and inclusive education. Int. El. J. of El. Ed. 4(3), 563-571 (2017)

10. S. Symeonidou, H. Phtiaka, Using teachers' prior knowledge, attitudes and beliefs to develop inservice teacher education courses for inclusion. Teach. and Teach. Ed. 25(4), 543-550 (2009). doi:10.1016/j.tate.2009.02.001

11. The Law of Ukraine "On Education" (2017), http://zakon3.rada.gov.ua/laws/show/2145-19. Accessed 25 Oct 2019

12. The Resolution of the Cabinet of Ministers of Ukraine "On Amendments to the Procedure for Organizing the Inclusive Learning in General Educational Institutions" (2017), https://zakon.rada.gov.ua/laws/show/588-2017$\%$ D0\%BF. Accessed 25 Oct 2019 